\title{
PELATIHAN PEMASARAN ONLINE PRODUK INDUSTRI KREATIF DI DESA LAKSANA MEKAR, KECAMATAN PADALARANG, KABUPATEN BANDUNG BARAT
}

\author{
Sam'un Jaja Raharja, Arianis Chan, Nenden Kostini, dan Herwan Abdul Muhyi \\ Universitas Padjadjaran \\ E-mail: s.raharja2017@unpad.ac.id
}

\begin{abstract}
ABSTRAK. Penelitian ini bertujuan untuk menganalisis pemasaran produk industri kreatif pada komunitas Ecovillage Wilayah Citarum di Desa Laksana Mekar Kecamatan Padalarang Kabupaten Bandung Barat. Berdasarkan analisis situasi terdapat kendala dalam pemasaran produk tersebut secara langsung yang disebabkan oleh keterbatasan waktu untuk memasarkan dan keterbatasan tempat pemasaran (outlet). Untuk mengatasi kendala tersebut dan berdasarkan hasil diskusi dengan komunitas Ecovillage, maka salah satu alternatif solusi yang dipilih dan diputuskan adalah dengan melakukan pemasaran secara online (online marketing). Pelatihan diberikan untuk memberikan pengetahuan dan ketrampilan dalam memasarkan produk secara online. Metode pelatihan yang diberikan berupa hakekat pemasaran, dasar-dasar pemasaran online dan praktek pembuatan fitur-fitur pemasaran online dengan menggunakan smart phone. Hasil pelatihan menunjukkan telah terjadi perubahan pengetahuan dan ketrampilan para peserta dalam teori dan praktek pemasaran produk secara online. Disarankan agar ada kegiatan pendampingan lanjutan sejalan dengan perkembangan teknolog informasi yang cepat dan dinamis
\end{abstract}

Kata kunci: industri kreatif; pemasaran online; ecovillage; Wilayah Citarum; Desa Laksanamekar

\section{ONLINE MARKETING TRAINING OF CREATIVE INDUSTRY PRODUCTS IN LAKSANA MEKAR VILLAGE PADALARANG DISTRICT, WEST BANDUNG REGENCY}

\begin{abstract}
This study aims to analyze the marketing of creative industry products in the Ecovillage community of the Citarum Region in Laksana Mekar Village, Padalarang District, West Bandung Regency. Based on the analysis of the situation there are obstacles in marketing the product directly caused by limited time to market and limitations of marketing places (outlets). To overcome these obstacles and based on the results of discussions with the Ecovillage community, one alternative solution that was chosen and decided was to do online marketing. Training is given for provide knowledge and skills in marketing products online. The training methods provided are the essence of marketing, the basics of online marketing and the practice of making online marketing features using a smart phone. The results of the training show that there has been a change in the knowledge and skills of the participants in the theory and practice of marketing products online. It is recommended that there be further assistance in line with the rapid and dynamic development of information technology
\end{abstract}

Key words: creative industry; online marketing; ecovillage; Citarum River; Laksanamekar Village

\section{PENDAHULUAN}

Sungai Citarum merupakan salah satu sungai terpanjang di Indonesia. Banyak sekali aktivitas masyarakat yang berada di sepanjang Daerah Aliran Sungai Citarum. Salah satu aktivitas yang dilakukan oleh masyarakat adalah pemeliharaan kelestarian dan kebersihan sungai Citarum. Aktivitas ini kemudian dikenal dengan nama Ecovillage. Salah satu aktivitas Ecovillage adalah memanfaatan barang bekas.khususnya yang berasal dari berbagai sampah plastik untuk diolah menjadi produk industri kreatif.

Dalam proses selanjutnya ditemukan permasalahan alam proses distribusi dan penyaluran kepada konsumen industri maupun konsumen akhir. Kendala yang dihadapi adalah terbatasnya waktu yang dimiliki dan terbatasnya outlet untuk memasarkan secara langsung. Kondisi ini menyebabkan penayaluran dan pemasaran menjadi terkendala. Berdasarkan identifikasi potensi, peluang dan kendala aktivitas bisnis di tersebut, dibutuhkan suatu upaya pengembangan potensi bisnis tersebut secara optimal, baik secara teknis operasional maupun etos kerja kewirausahaan melalui sebuah kegiatan Pelatihan. Salah satu yang dapat dilakukan adalah dengan memanfaatkan Teknologi Informasi dan Komunikasi (TIK).

Wahid dan Iswari (2007) menyatakan adopsi Teknologi Informasi Komunikasi (TIK) dikalangan usaha kecil, termasuk dalam hal ini usaha-usaha yang dilakukan oleh komunitas di Indonesia masih sangat rendah. Penggunaan Teknologi Informasi oleh Usaha Mikro, Kecil dan Menengah (UMKM) belum menyentuh tataran strategis. Mengacu kepada Knol dan Stroken (2001) adopsi Teknologi Informasi sebagian besar UMKM di Indonesia masih dalam tingkat 1, dalam arti masih masih pada tataran intergasi fungsional yang berorientasi internal. Hal ini dapat dlihat pada tabel skenario adopsi teknologi berikut ini;

Tabel 1. Skenario Adopsi Teknologi Informasi oleh UMKM

\begin{tabular}{|c|c|}
\hline Tingkat & Keterangan \\
\hline 0 & Tidak menggunakan Teknologi Informasi \\
\hline 1 & Integrasi fungsional yang berorientasi internal \\
\hline 2 & Integrasi multifungsional yang berorientasi eksternal \\
\hline 3 & Integrasi proses yang berorientasi eksternal \\
\hline 4 & $\begin{array}{l}\text { Perancangan ulang proses bisnis (business process } \\
\text { redesaign) }\end{array}$ \\
\hline 5 & $\begin{array}{l}\text { Redefinisi lingkup bisnis dengan bantuan Teknologi } \\
\text { Informasi }\end{array}$ \\
\hline
\end{tabular}

Kapurubandara dan Lawson (dalam Wahid dan Iswari, 2007), mengelompokkan hambatan adopsi Teknologi Informasi dikalangan UMKM kedalam hambatan internal dan hambatan eksternal. Termasuk dalam hambatan internal 
adalah karakteristik dan manajemen dan UMKM. Sedangkan keterbatasan infrastruktur dan kondisi sosial dan kultural adalah contoah hambatan eksternal. Hambatan internal dapat diselesaikan dengan dukungan penuh didalam perusahaan. Sedangkan hambatan eksternal harus melibatkan pihak eksternal untuk memecahkan masalah tersebut. Melihat scenario yang dikemukakan di atas, dapat dikatakan bahwa situasi penggunanaan Teknologi Informasi pada komunitas Ecovillage masih daplam tingkatan 0 atau belum menggunakan Teknologi Informasi

Kementerian Perdagangan (2008) mendefinisikan "Industri kreatif adalah industri yang berasal dari pemanfaatan kreativitas, keterampilan serta bakat individu untuk menciptakan kesejahteraan serta lapangan pekerjaan dengan menghasilkan dan mengeksploitasi daya kreasi dan daya cipta individu tersebut. Sub-sektor yang merupakan industri berbasis kreativitas di Indonesia berdasarkan pemetaan yang dilakukan Departemen Perdagangan Republik Indonesia adalah sebagai berikut (1) Periklanan (2) Arsitektur (3) Pasar Barang Seni (4) Kerajinan (5) Desain (6) Fesyen (7) Video (8) Permainan Interaktif (9) Musik (10) Penerbitan dan Percetakan (11) Layanan Komputer (12) Televisi dan Radio (13) Riset dan Pengembangan (14) Kuliner (15) Permainan Game Interaktif. Bisnis atau industri Kreatif diartikan sebagai kumpulan aktivitas ekonomi yang terkait dengan penciptaan atau penggunaan pengetahuan dan informasi, yang juga dikenal dengan istilah lain Industri Budaya atau juga Ekonomi Kreatif (Hesmonddhalgh, 2002; Howkins 2014).

Berdasarkan uraian tersebut di atas, dapat diidentifikasi permasalahan sebagai berikut: Kegiatan pelatihan apa yang dibutuhkan agar potensi bisnis industri kreatif dapat dikembangkan dan ditingkatkan dengan memanfaatkan teknologi informasi? Materi-materi pelatihan apa yang sesuai untuk diberikan kepada para peserta. Pelatihan ini bertujuan untuk mengidentifikasi potensi dan peluang dan aktivitas bisnis kreatif Komunitas Ecovillage di wilayah Daerah Aliran Sungai Citarum dan memberikan pengetahuan dan pemahaman tatacara dalam pemasaran hasil indutsri melalui media online dengan cara mengadopsi dan mengaplikasikan teknologi informasi dan komunikasi (TIK).

Kecamatan Padalarang merupakan salah satu kecamatan di Kabupaten Bandung Barat. Pelaku industri kreatif di adalah para penggiat lingkungan yang tergabung dalam komunitas Eco Village Sektor 9. Khalayak sasaran dalam kegiatan Pengabdian Kepada Masyarakat yang akan dilakukan ini sebanyak 50 penggiat yang tersebar di Desa Jaya Mekar dan Desa Laksana Mekar. Tempat kegiatan dilaksanakan di Aula SMA 2 Padalarang Kabupaten Bandung Barat.

Desa Laksana Mekar merupakan salah satu Desa di Kecamatan Padalarang. Secara geografis berbatasan dengan desa lainnya yaitu sebelah utara Desa Gado Bangkong Kecamatan Ngamprah. Sebelah selatan Desa Giri Asih Kecamatan Batujajar. Sebelah Timur Desa Cibeber Kecamatan Cimahi Selatan (Kota Cimahi). Sebelah barat Desa Cimerang Kecamatan Padalarang. Total luas wilayah saat ini adalah 470,71
Ha. Sebagian besar luas wilayah adalah tanah kering (125 ha) dan Perkebunan 146 ha. Penggunaannya mayoritas untuk perkebunan 146 ha, pemukiman 107 ha dan perkantoran 133 ha. Sisanya berupa persawahan, prarasana umum, pekarangan, taman dan kuburuan

Pada saat ini jumlah penduduk Desa Laksana Mekar berjumlah 17.877 jiwa yang terdiri dari laki-laki 9.097 orang dan perempuan 8.780 orang. Dari sudut Kepala Keluarga berjumlah $5.365 \mathrm{KK}$. Jika dilihat dari pekerjaan atau matapencaharian, secara berurutan didominasi oleh karyawan perusahan swasta, disusul TNI/Polri, PNS buruh tani, petani, pengusaha skala UKM, penisunan dan karyawan BUMN. Menurut tingkat perkembangannya, Desa Laksana Mekar termasuk dalam kategori Swakarya dengan kategori perkembangan Madya

\section{METODE}

Online marketing merupakan salah satu model dalam pemasaran suatu produk, termasuk produk industri kreatif yang dihasilkan oleh komunitas Ecovillage di wilayah DAS Citarum. Bagi komunitas, pemasaran online dapat memecahkan kendala-kendala yang dihadapi seperti keterbatasan waktu, tempat dan saluran pemasaran. Melalui pemasaran online ketiga hal tersebut dapat diatasi

Metoda yang digunakan dalam hal ini adalah dengan memberikan pelatihan pemasaran secara online bagi komunitas Ecovillage di Kecamatan Padalarang Kabupaten Bandung Barat. Pelatihan online marketing meliputi (1) pemaparan teoritis pengetahuan umum tentang Teknologi Informasi dan (2) praktek langsung penggunaan Teknologi Informasi dan Komunikasi dengan menggunakan smart phone

\section{HASIL DAN PEMBAHASAN}

Melalui Pelatihan Pemasaran Online, pengetahuan para peserta dari Desa Jayamekar dan Desa Laksanamekar mengenai pemasaran secara online secara umum mengalami peningkatan sebesar $18.75 \%$. Sebelum dilakukan Pelatihan Pemasaran Oline, sebagian warga belum tahu prinsip-prinsip marketing online dan cara menggunakan media sosial sebagai marketplace. Setelah mengikuti pelatihan, warga sudah mulai mengetahui prinsip marketing online dan cara menggunakan media sosial sebagai marketplace.

Peningkatan pengetahuan tentang marketing dimana: sebelum diadakannya pelatihan, skor yang didapatkan adalah 2.3125 dari 5 poin, sementara setelah diadakan pelatihan, skor yang didapatkan adalah 3.125 dari 5 poin, atau terjadi peningkatan sebesar 0.8125 poin. Artinya setelah mengikuti pelatihan, pengetahuan peserta mengenai marketing mengalami peningkatan sebesar $16.25 \%$.

Peningkatan pengetahuan mengenai marketing online dimana sebelum diadakannya pelatihan, skor yang didapatkan adalah 2.1875 dari 5 poin, sementara setelah diadakan pelatihan, skor yang didapatkan adalah 3.125 dari 
5 poin atau terjadi peningkatan sebesar 0.9375 poin. Artinya setelah mengikuti pelatihan, pengetahuan peserta mengenai marketing online mengalami peningkatan sebesar $18.75 \%$.

Peningkatan pengetahuan mengenai media sosial: sebelum diadakannya pelatihan, skor yang didapatkan adalah 2.75 dari 5 poin, sementara setelah diadakan pelatihan, skor yang didapatkan adalah 3.375 dari 5 poin atau terjadi peningkatan sebesar 0.625 poin. Artinya setelah mengikuti pelatihan, pengetahuan peserta mengenai media sosial mengalami peningkatan sebesar $12.5 \%$.

Pengetahuan mengenai Facebook: sebelum diadakannya pelatihan, skor yang didapatkan adalah 2.375 dari 5 poin, sementara setelah diadakan pelatihan, skor yang didapatkan adalah 3.25 dari 5 poin atau terjadi peningkatan sebesar 0.875 poin. Artinya setelah mengikuti pelatihan, pengetahuan peserta mengenai Facebook mengalami peningkatan sebesar 17.5\%.

Pengetahuan mengenai Facebook Marketplace: sebelum diadakannya pelatihan, skor yang didapatkan adalah 1.875 dari 5 poin, sementara setelah diadakan pelatihan, skor yang didapatkan adalah 2.87 dari 5 poin atau terjadi peningkatan sebesar 1 poin. Artinya setelah mengikuti pelatihan, pengetahuan peserta mengenai Facebook Marketplace mengalami peningkatan sebesar $20 \%$.

Pengetahuan mengenai kegunaan Facebook Marketplace: sebelum diadakannya pelatihan, skor yang didapatkan adalah 1.8125 dari 5 poin, sementara setelah diadakan pelatihan, skor yang didapatkan adalah 2.75 dari 5 poin atau terjadi peningkatan sebesar 0.9357 poin. Artinya setelah mengikuti pelatihan, pengetahuan peserta mengenai kegunaan Facebook Marketplace mengalami peningkatan sebesar 18.75\%.

Pengetahuan mengenai cara menggunakan Facebook Marketplace: sebelum diadakannya pelatihan, skor yang didapatkan adalah 1.687 dari 5 poin, sementara setelah diadakan pelatihan, skor yang didapatkan adalah 2.8125 dari 5 poin atau terjadi peningkatan sebesar 1.125 poin. Artinya setelah mengikuti pelatihan, pengetahuan peserta mengenai cara menggunakan Facebook Marketplace mengalami peningkatan sebesar $22.5 \%$

Pengetahuan mengenai fungsi caption: sebelum diadakannya pelatihan, skor yang didapatkan adalah 1.8125 dari 5 poin, sementara setelah diadakan pelatihan, skor yang didapatkan adalah 2 dari 5 poin atau terjadi peningkatan sebesar 0.1875 poin. Artinya setelah mengikuti pelatihan, pengetahuan peserta mengenai fungsi caption mengalami peningkatan sebesar $3.75 \%$.

Pengetahuan mengenai cara membuat caption yang baik : sebelum diadakannya pelatihan, skor yang didapatkan adalah 1.8125 dari 5 poin, sementara setelah diadakan pelatihan, skor yang didapatkan adalah 2.75 dari 5 poin atau terjadi peningkatan sebesar 0.9375 poin. Artinya setelah mengikuti pelatihan, pengetahuan peserta mengenai cara membuat caption yang baik mengalami peningkatan sebesar $18.75 \%$.

Pengetahuan mengenai fungsi hashtag/tagar: sebelum diadakannya pelatihan, skor yang didapatkan adalah 1.75 dari 5 poin, sementara setelah diadakan pelatihan, skor yang didapatkan adalah 2.9375 dari 5 poin atau terjadi peningkatan sebesar 1.1875 poin. Artinya setelah mengikuti pelatihan, pengetahuan peserta mengenai fungsi hashtag/tagar mengalami peningkatan sebesar $23.75 \%$.

Pengetahuan mengenai cara pengambilan foto yang baik: sebelum diadakannya pelatihan, skor yang didapatkan adalah 2.1875 dari 5 poin, sementara setelah diadakan pelatihan, skor yang didapatkan adalah 3 dari 5 poin atau terjadi peningkatan sebesar 0.8125 poin. Artinya setelah mengikuti pelatihan, pengetahuan peserta mengenai cara pengambilan foto yang baik mengalami peningkatan sebesar 16.25\%.

Pengetahuan mengenai fungsi branding: sebelum diadakannya pelatihan, skor yang didapatkan adalah 1.8125 dari 5 poin, sementara setelah diadakan pelatihan, skor yang didapatkan adalah 3.25 dari 5 poin atau terjadi peningkatan sebesar 1.4375 poin. Artinya setelah mengikuti pelatihan, pengetahuan peserta mengenai fungsi branding mengalami peningkatan sebesar $28.75 \%$.

\section{SIMPULAN}

Pelatihan yang diberikan pelatihan memberikan pengetahuan dan ketrampilan kepada para pelaku usaha dalam membuat aplikasi sederhana pemasaran online pada usaha yang dijalannkannya. Pelatihan Pelatihan Pemasaran Oline Produk Industri Kreatif Komunitas Ecovillage Sektor 9 Desa Laksana Mekar Kecamatan Padalarang Kabupaten Bandung Barat telah memberikan dampak signifikan. Dampak tersebut dapat dilihat dari adanya penambahan pengetahuan peserta mengenai prinsip marketing online dan cara menggunakan media sosial sebagai marketplace. Demikian juga dengan pengetahuan peserta mengenai pemasaran secara online secara umum mengalami peningkatan. Untuk keberlanjutan program diperlukan pendampingan lebih lanjut dalam penyusunan dan pembuatan konten-konten online marketing dan penyusunan pembukuan sederhana. Hal ini mengingat perkembangan teknologi start up selalu berkembang sehingga fitur-fitur baru senantiasa diperkenalkan

\section{DAFTAR PUSTAKA}

Hesmondhalgh. D. (2012) The Cultural Industries. $3^{\text {rd }}$ Edition. SAGE Publications

Howkins, J. (2014) The Creative Economy. How people make money from ideas, The Penguin Press

Knol, W. H. C., dan Stroeken, J. H. M. (2001). The Diffusion and Adoption of Information Technology in Smalland Medium-sized Enterprises through IT Scenarios. Technology Analysis \& Strategic Management, 13(2).

Putu Sukarmen, Andi Sularso dan Deasy Wulandari. (2013). Analisis Pengaruh Inovasi Produk Terhadap Kepuasan Konsumen Dengan Keunggulan Bersaing Sebagai Variabel Intervening Pada Produk Gula Pasir Sebelas (GUPALAS) Pabrik Gula Semboro PTP Nusantara XI (Persero). JEAM, Vol. XII No. 1. Hal. 64-78. ISSN: 1412-5366 
Februati, S. E. dan Handayani, S.R (2012) Peranan Aplikasi Teknologi Informasi dalamPeningkatan Daya Saing Perusahaan (Studi Pada UMKM Kota Malang). Prosiding Seminar Nasional Manajemen Teknologi XV. Surabaya. Program MMT-ITS
Wahid, F. dan Iswari, L (2007) Adopsi Teknologi Informasi oleh Usaha Kecil Menengah di Indonesia. Prosiding Seminar Nasional Aplikasi Teknologi Informasi 2007 (SNATI 2007) ISSN: 1907-5022. Yogyakarta

Departemen Perdagangan Republik Indonesia (2008). Pengembangan Industri Kreatif Menuju Visi Ekonomi Kreatif Indonesia 2025. 